\title{
$\begin{array}{ll}\text { Research Square } & \text { Preprints are preliminary reports that have not undergone peer review. }\end{array}$ or referenced by the media as validated information. \\ Unexpected Echocardiographic Findings: Accessory Mitral Valve Tissue in Adults
}

\section{Ying Rao}

Kunming Medical University First Affilliated Hospital

\section{Wei Chen}

Kunming Medical University First Affilliated Hospital

Yu Wang ( $\sim$ kmyuerhui@163.com )

Kunming Medical University First Affilliated Hospital https://orcid.org/0000-0001-7698-7663

wenjuan Song

Kunming Medical University First Affilliated Hospital

\section{Case report}

Keywords: Accessory mitral valve tissue, Congenital, Cardiac magnetic resonance imaging, Echocardiography, Three-dimensional echocardiography

Posted Date: November 9th, 2020

DOI: https://doi.org/10.21203/rs.3.rs-102531/v1

License: (1) (1) This work is licensed under a Creative Commons Attribution 4.0 International License. Read Full License 


\title{
Unexpected echocardiographic findings: Accessory Mitral Valve Tissue in Adults
}

\author{
Ying Rao MD ${ }^{1}$, Wei Chen MD, $\mathrm{PhD}^{2}$, Wenjuan Song $\mathrm{MD}^{1}$, Yu Wang MD,PhD ${ }^{1}$ \\ ${ }^{1}$ Department of Cardiology, The First Affiliated Hospital of Kunming Medical University, Kunming, \\ China \\ ${ }^{2}$ Department of Radiology, The First Affiliated Hospital of Kunming Medical University, Kunming, \\ China
}

\section{Correspondence}

Yu Wang, MD,PhD, Department of Cardiology, The First Affiliated Hospital of Kunming Medical University, 256 Xi Chang Road, Kunming, Yunnan Province, 650032, P.R. China.

Email: kmyuerhui@163.com

\section{Co-Authors}

Ying Rao,MD, Email: 2336942101@qq.com; Wei Chen, MD,PhD, Email: chenwin2008@139.com;

Wenjuan Song, MD, Email: 59899947@qq.com 


\section{ABSTRACT}

Background: Accessory mitral valve tissue (AMVT) is a rare congenital cardiac anomaly, which is associated with other congenital heart diseases. It is diagnosed in neonates or childhood and rarely in adulthood. Nevertheless, AMVT is an incidental finding or described as isolated. Echocardiography, especially three-dimensional(3D) echocardiography is considered as an optimal imaging technique for AMVT diagnosis.

Case presentation: We herein presented the two asymptomatic adult cases with AMVT, who presented with varying degrees of symptomatic left ventricular outflow tract (LVOT) obstruction. One presented with mild LVOT obstruction and no surgery was required, and another one with significant LVOT obstruction was recommended for surgical excision.

Conclusions: We emphasized the usefulness of echocardiography in the morphology detection of AMVT, and the importance of operation guidance and follow-up.

Keywords: Accessory mitral valve tissue, Congenital, Cardiac magnetic resonance imaging, Echocardiography, Three-dimensional echocardiography 


\section{Background}

Assisted mitral valve tissue (AMVT) was first reported as early as 1842 by Chevers et al ${ }^{1}$, as a rare congenital cardiac anomaly. Symptomatology of the patient commonly manifest asymptomatic heart murmur or symptoms of LVOT obstruction, such as chest pain, syncope, or palpitations ${ }^{4,5}$. Although AMVT is often associated with other congenital heart diseases ${ }^{2}$, it may be seen as isolated. It is often detected in neonates or childhood and rarely in adults ${ }^{3}$. Three-dimensional(3D) echocardiography is considered as an optimal imaging technique for AMVT diagnosis. We herein presented the two asymptomatic adult cases with AMVT, who presented with varying degrees of symptomatic left ventricular outflow tract (LVOT) obstruction. One presented with mild LVOT obstruction and no surgery was required, and another one with significant LVOT obstruction was recommended for surgical excision.

\section{Case presentation}

\section{Case 1}

A 33-year-old man with a medical history of ventricular septal defect (VSD) repair surgery in seven years ago, and no other comorbidity, was referred to cardiology services for assessment on July, 2018. He didn't have any history of chest pain, dyspnea or syncope. On admission, his vital signs were normal. At the left sternum, physical examination revealed a systolic murmur of the third and fourth intercostal spaces were $2 / 6$ grade medium, and there was no radiation to the neck. The electrocardiogram was unremarkable. Other laboratory data were also normal. Two-dimensional (2D) transthoracic echocardiography (TTE) revealed a mobile, echogenic, membrane-like structure attached to the ventricular side of the proximal part of the anterior mitral leaflet. During the systole, 
gradually move into the LVOT and occupied the sub-aortic region, thus proving the description of AMVT (Figure1, Video1). Further evaluation indicated a systolic trace turbulent flow pattern with mild obstruction of LVOT generating a peak velocity of 2.3 meters per second, with a maximum gradient of $27 \mathrm{mmHg}$ (Figure1, Video2). Any morphological and functional abnormalities were not observed in the mitral valve and tricuspid valve, but a mild aortic regurgitation was detected on 2D color Doppler TEE. No residual shunt was described after the ventricular septal repair. All cavities diameters were within normal limits. TTE also revealed preserved biventricular systolic function (left ventricular ejection fraction :77\%) with normal segmental contractility. 3D echocardiography illustrated that the membrane-like structure in the LVOT was attached between to the rudimentary chordae tendineae of the anterior MV leaflet and the left side of basal interventricular septum (Figure2, Video3). Mobile AMVT was attached to the A1 segment free edge. During hospitalization, the patient underwent cardiac magnetic resonance (CMR) to exclude the possibility of cardiac masses and to further clarify its dimension and location (Fig.3).

Even if the AMVT was not identified in the patient's previous echocardiographic examinations in another cardiac institute, the current diagnosis of AMVT was clear. Given that there were no significant LVOT obstructions or symptoms, we considered that surgery is unnecessary. The patient was advised echocardiographic follow up and aspirin therapy to reduce the risk of thromboembolism events. At one year of follow-up, no significant changes in morphology and LVOT obstruction were caught by echocardiography. This patient did not have any new cardiac adverse events. 


\section{Case 2}

A 46-year-old woman was transferred from cardiovascular Surgery Department to our clinic for the reassessment of patient before surgery. There was no any sign on physical examination other than a 3/6 systolic ejection murmur with faint radiation to the neck. TTE showed normal-sized cardiac chambers and the left ventricular ejection fraction was 0.79 . Concurrently, ascending aorta dilatation was also found with diameter up to $37 \mathrm{~mm}$ with mild to moderate aortic regurgitation. Abnormal membranous structure, mobile, attached to the ventricular side of anterior mitral leaflet was seen, causing LVOT occlusion during systole. The maximal pressure gradient measured was 64 $\mathrm{mmHg}$ and speed were $4.0 \mathrm{~m} / \mathrm{s}$ (Figure4, Videos4 and 5). No other congenital heart anomalies were presented. A diagnosis of AMVT with severe obstruction of the left ventricular outflow tract based on echocardiographic characteristics was made.

The patient underwent an operation under standard cardiopulmonary bypass on December 27th,2019. Intraoperative transesophageal echocardiography (TEE) before cardiopulmonary bypass revealed a mobile, membrane-like structure that prolapsed into the LVOT with a sac shape during diastole and occupying the LVOT obstructing systole with extended parachute structure (Figure5, Videos 5 and 6). Autotomy in combination with right atriotomy and the transseptal approach was undertaken. The mitral valve was repaired with a $30 \mathrm{~mm}$ Physio ring. Histological examination showed myxomatous degeneration analogous to dysplastic valvular tissue (Figure6). Postoperatively, TTE demonstrated that there was no residual accessory mitral tissue and mitral regurgitation. The patient was discharged on the twelfth day after the operation and had no symptoms after 6 months of follow-up. 


\section{Discussion}

AMVT is a rare congenital malformation, which may be caused by abnormal or incomplete separation of the mitral valve from the endocardial cushions ${ }^{1}$. It may be isolated or combined with other congenital heart anomalies. The usual age range for diagnosis of AMVT was from newborn to 77 years (average 8.6 years), while the incidence of AMVT in adults was $1 / 26,000$ based on echocardiography ${ }^{4}$. Prifti et al ${ }^{6}$. provided a classification of this anomaly based on intraoperative description and anatomic presentation. As to AMVT morphology, sac-like, balloon-like, parachutelike, sail, leaflet-like, sheet, membrane, or pedunculated mass were demonstrated ${ }^{8}$. The patients in our case had a mobile leaflet-like structure and no well-developed chordae tendineae. Therefore, we classified our cases into Type IIB1. Echocardiography can clarify the morphology and attachment points of the AMVT, particularly in patients scheduled for surgery ${ }^{11,12}$. Typically, we need to differentiate AMV from redundant mitral valve chordae and other structures in LVOT. For example, redundant mitral valve chordae may be involved in chordal systolic anterior motion with dynamic LVOT obstruction and similar to AMVT in case of chordal rupture ${ }^{10}$. We could also choose cardiac computed tomography and CMR, especially CMR to provide not only validation of AMVT types but also volume quantification for obstruction. Identifying AMVT during operation is not always possible, bypass causing collapse of the thin structure in empty and arrested left ventricle. In the patient of our case 1, the AMVT was not identified when VSD was repaired seven years ago.

Symptoms of patients with AMVT depend on the degree of LVOT obstruction, knock-on effects on the aortic and mitral valves and on concomitant cardiovascular malformations ${ }^{7}$. Just like the patient in our case 2 , whom has an obvious LVOT obstruction (> 50mmHg) with associated symptoms and 
eventually undergo surgical treatment. In addition, AMVT is susceptible to embolism of the neurological events, so surgery is also recommended ${ }^{13}$. For patients without severe LVOT obstruction, a serial echocardiographic follow-up is recommended to assess the progression of the gradient without the need for prophylactic operation.

\section{Conclusion}

AMVT is a rare congenital cardiac abnormality with various clinical manifestations, which also results in one of the rare causes of LVOT obstruction. It should be always considered in the differential diagnosis of LVOT obstruction, especially in pre-or post-operative of congenital heart disease patients. Hence, echocardiography plays a crucial role in diagnosis, treatment and follow-up.

\section{Abbreviations}

AMVT: Accessory mitral valve tissue; 2D: two-dimensional; 3D: three dimensional; CMR: Cardiac magnetic resonance; LVOT: left ventricular outflow tract; TEE: Intraoperative transesophageal echocardiography; TTE: transthoracic echocardiography; VSD: ventricular septal defect.

\section{Acknowledgements}

Not applicable.

\section{Authors' contributions}

All authors contributed to manuscript revision, read and approved the submitted version. 


\section{Authors' information}

Not applicable

\section{Funding}

The Yunnan Applied Basic Research Projects. Grant /Award Numbers: 2018FE001(-036).

\section{Availability of data and materials}

The data of this study are available from the corresponding author upon request.

\section{Ethics approval and consent to participate}

The patient has consented to the submission of the case report for submission to the journal. The consent form is held by the authors and is available for review.

\section{Consent for publication}

Yes

\section{Competing interests}

The authors declare that they have no conflict of interest.

\section{References}

1. Manganaro R, Zito C, Khandheria B K, et al. Accessory mitral valve tissue: an updated review of the literature. Eur Heart J-Card Img 2014; 15:489-497. 
2. Chevers N. Observations on diseases of the orifice and valves of the aorta. Guys Hosp Rep 1842; 7:387452.

3. Yuan SM, Shinfeld A, Mishaly D, et al. Accessory mitral valve tissue: a case report and an updated review of literature. J Card Surg 2008; 23:769-772.

4. Rovner A, Thanigaraj S, Perez JE. Accessory mitral valve in an adult population: the role of echocardiography in diagnosis and management. J Am Soc Echocardiogr 2005;18: 494-498.

5. Iba Y, Saito S, Kawai A, Kurosawa H. Images in cardiovascular medicine. Mitral valve prolapse associated with accessory mitral valve. Circulation 2005;111: e107.

6. Prifti E, Bonacchi M, Bartolozzi F, Frati G, Leacche M, Vanini V. Postoperative outcome in patients with accessory mitral valve tissue. Med Sci Monit 2003;9:RA126-133.

7. Aoka Y, Ishizuka N, Sakomura Y, Nagashima H, Kawana M, Kawai A, Kasanuki H. Accessory mitral valve tissue causing severe left ventricular outflow tract obstruction in an adult. Ann Thorac Surg 2004; 77: 713-715.

8. N. Rao, T. Gajjar, N. Desai, Accessory mitral valve tissue: an unusual cause of congenital mitral stenosis, Interactive Cardiovascular and Thoracic Surgery 2012;14:110-112.

9. Prifti E, Frati G, Bonacchi M, Vanini V, Chauvaud S. Accessory mitral valve tissue causing left ventricular outflow tract obstruction: case reports and literature review. J Heart Valve Dis 2001;10: 774-778.

10. Popescu BA, Ghiorghiu I, Apetrei E, Ginghina C. Subaortic stenosis produced by an accessory mitral valve: the role of echocardiography. Echocardiography 2005;22: 39-41.

11. Sharma R, Smith J, Elliott PM, McKenna WJ, Pellerin D. Left ventricular outflow tract obstruction caused by accessory mitral valve tissue. J Am Soc Echocardiogr 2006; 19:354.

12. Espinola-Zavaleta N, Vargas-Barro'n J, Keirns C, Rivera G, Romero-Ca'rdenas A, Rolda'n J et al. Three- 
dimensional echocardiography in congenital malformations of the mitral valve. J Am Soc Echocardiogr 2002;15: 468-472.

13. Yetkin E, Turhan $H$, Atak R, Senen $K$, Cehreli S. Accessory mitral valve tissue manifesting cerebrovascular thromboembolic event in a 34-year-old woman. Int J Cardiol 2003; 89:309-311.

\section{Figure legends}

Fig.1. Case 1. Five-chamber view, an abnormal membranous structure in the LVOT and attached to the anterior mitral leaflet. AMVT formed into a lump retracting to the LVOT during early diastole(a), prolapsed into the LVOT with a sac shape during mid diastole (b), and extended into a parachutestructure obstructing the LVOT during systole (c), Peak Pressure gradient of LVOT was $27 \mathrm{mmHg}(\mathrm{d})$.

Fig.2. Case 1. (a)Short-axis view of AMVT anatomy morphology. (b) 3D echocardiography demonstrated the relationship between the AMVT and sub valvular apparatus.

Fig.3. Case 1. Three-chamber view of CMR in the end of left ventricle systole, AMVT located in the middle of LVOT (white arrow) and mitral valve (blue arrow illustrated the mitral valve orifice).

Fig. 4. Case 2. (a)Transthoracic echocardiography in the apical long-axis view showed AMVT (arrow). (b) Continuous Doppler measurement traced the instantaneous gradient of $64 \mathrm{mmHg}$ at the proximal LVOT. 
Fig. 5. Case 2. (a)TEE,162-degree view, demonstrated the movement of AMVT being folded into LVOT. (b) Aliasing was clearly seen in LVOT with color Doppler flow frame. (c)3D rendering of the AMVT viewed from the bottom of the heart towards the apex in the long-axis view.

Fig. 6. Case 2. (a)Transaortic excision of a mobile mass resembling a leaflet, attached to the anterior mitral leaflet. (b)Histological examination (Hematoxylin-eosin stain) showed myxomatous degeneration.

\section{VIDEO HIGHLIGHTS}

Video 1 Case 1. Five-chamber view, an abnormal membranous structure in the LVOT and attached to the anterior mitral leaflet.

Video 2 Case 1. Continuous Doppler measurements tracked the color turbulence at the proximal LVOT.

Video 3 Case 1. 3D echocardiography demonstrated the relationship between the AMVT and sub valvular apparatus.

Video 4 Case 2. Transthoracic echocardiography in the apical long-axis view showed AMVT. Continuous Doppler measurement traced the instantaneous gradient of $64 \mathrm{mmHg}$ at the proximal LVOT. 
Video 5 Case 2. Continuous Doppler measurements tracked the color turbulence at the proximal LVOT.

Video 6 Case 2. TEE demonstrated the movement of AMVT and the aliasing in LVOT with color Doppler flow frame.

Video 7 Case 2.3D rendering of the AMVT viewed from the bottom of the heart towards the apex in the long-axis view. 


\section{Figures}

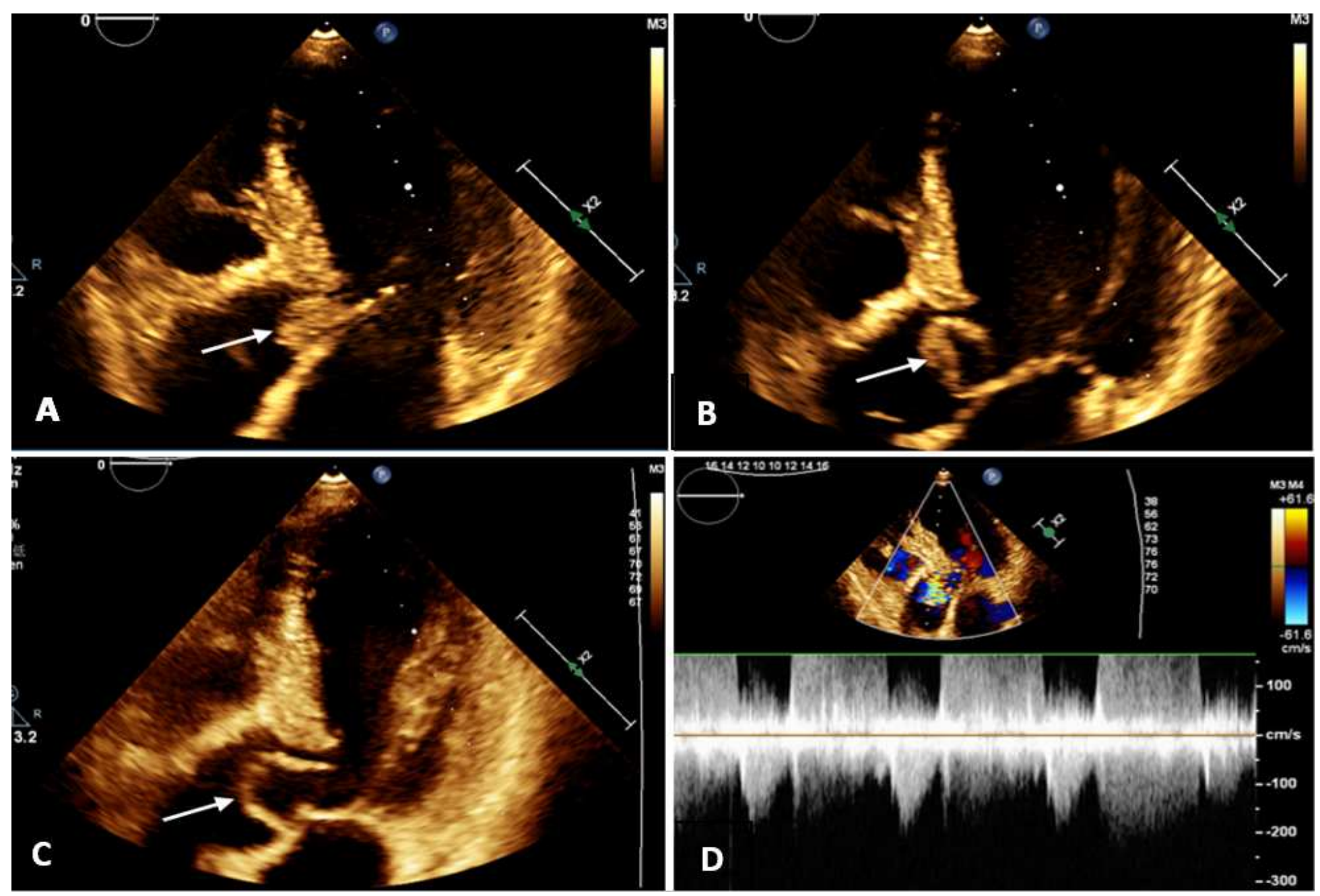

\section{Figure 1}

Case 1. Five-chamber view, an abnormal membranous structure in the LVOT and attached to the anterior mitral leaflet. AMVT formed into a lump retracting to the LVOT during early diastole(a), prolapsed into the LVOT with a sac shape during mid diastole (b), and extended into a parachute-structure obstructing the LVOT during systole (c), Peak Pressure gradient of LVOT was $27 \mathrm{mmHg}(\mathrm{d})$. 

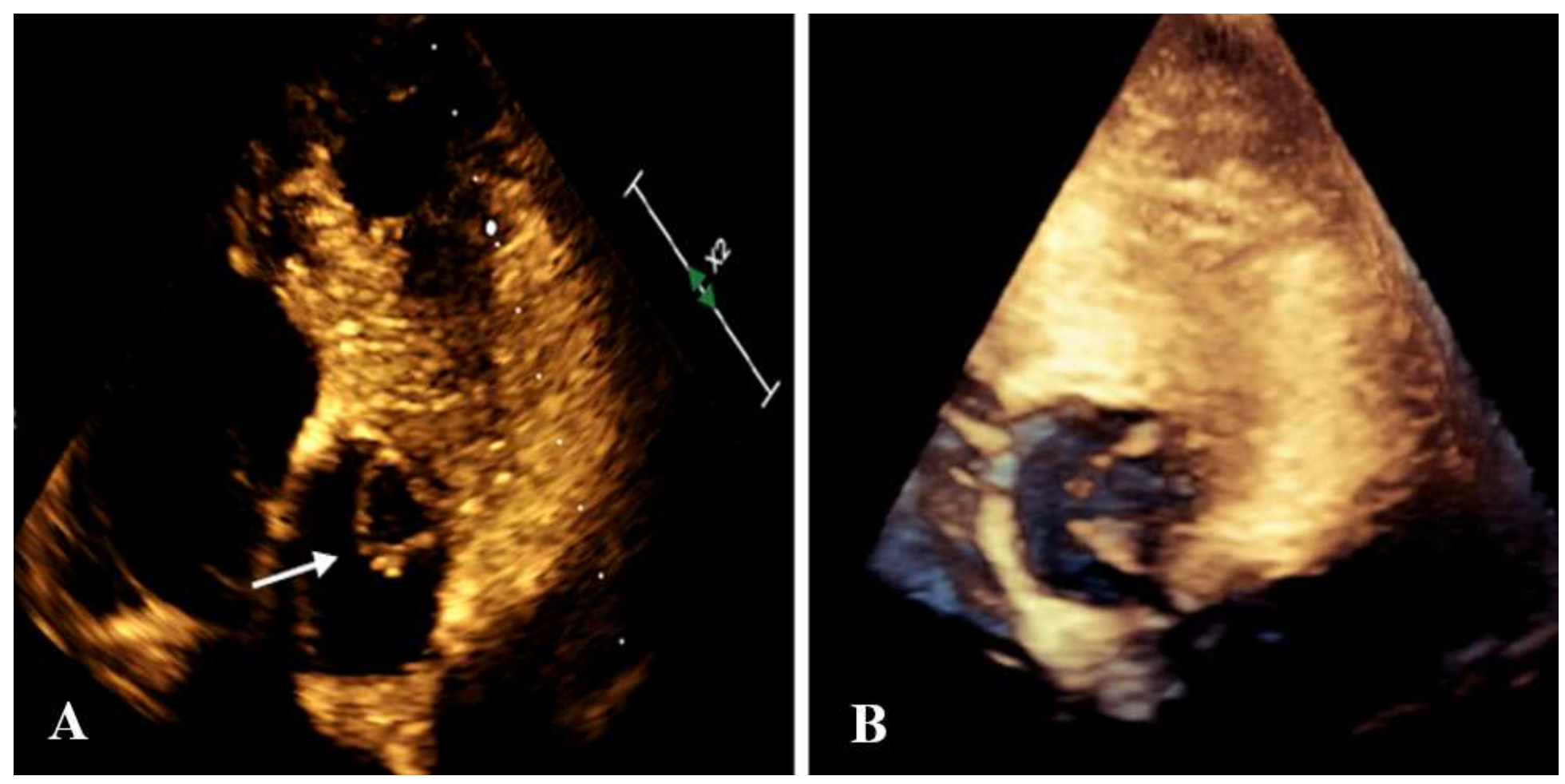

Figure 2

Case 1. (a)Short-axis view of AMVT anatomy morphology. (b) 3D echocardiography demonstrated the relationship between the AMVT and sub valvular apparatus. 


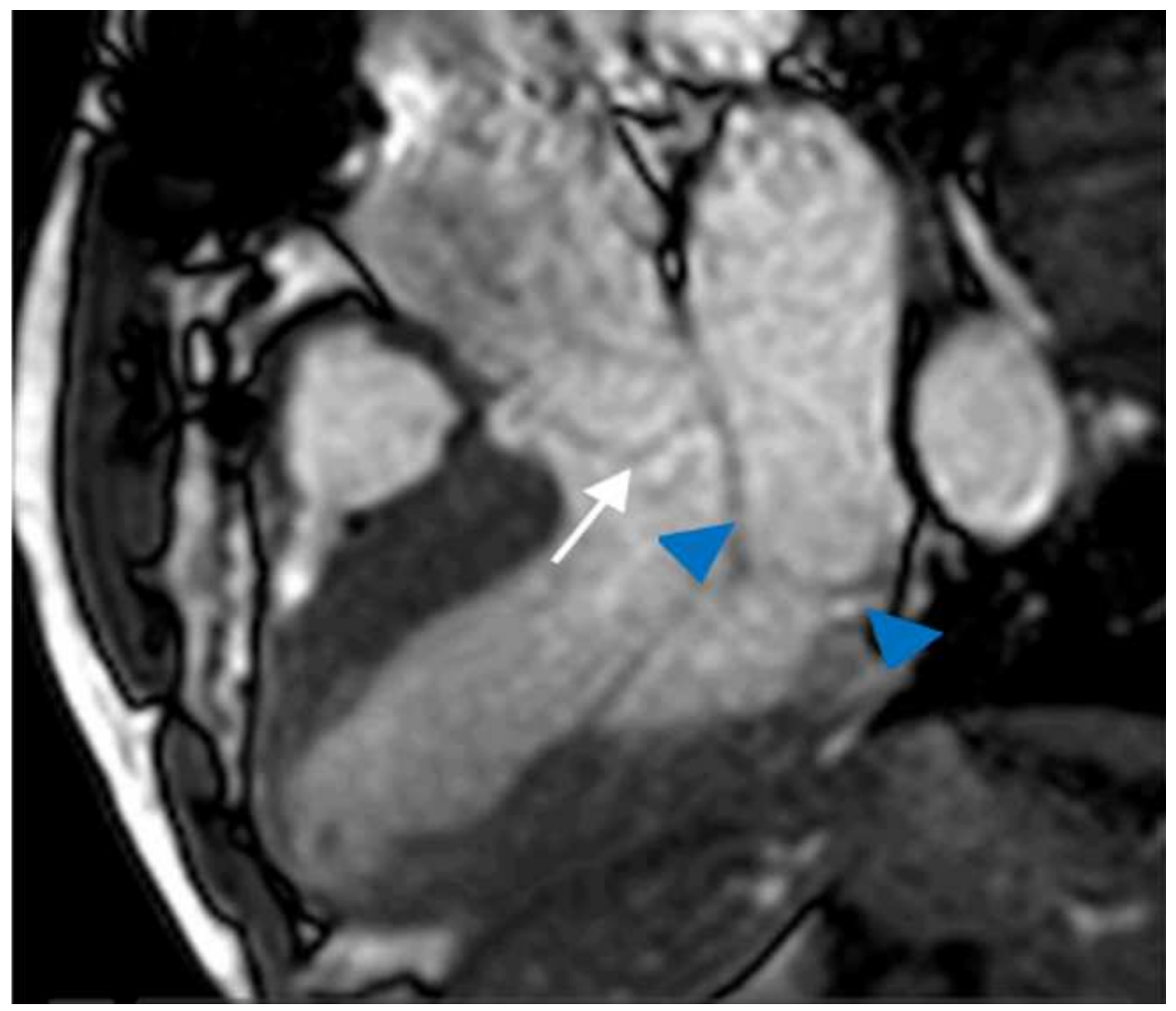

\section{Figure 3}

Case 1. Three-chamber view of CMR in the end of left ventricle systole, AMVT located in the middle of LVOT (white arrow) and mitral valve (blue arrow illustrated the mitral valve orifice). 

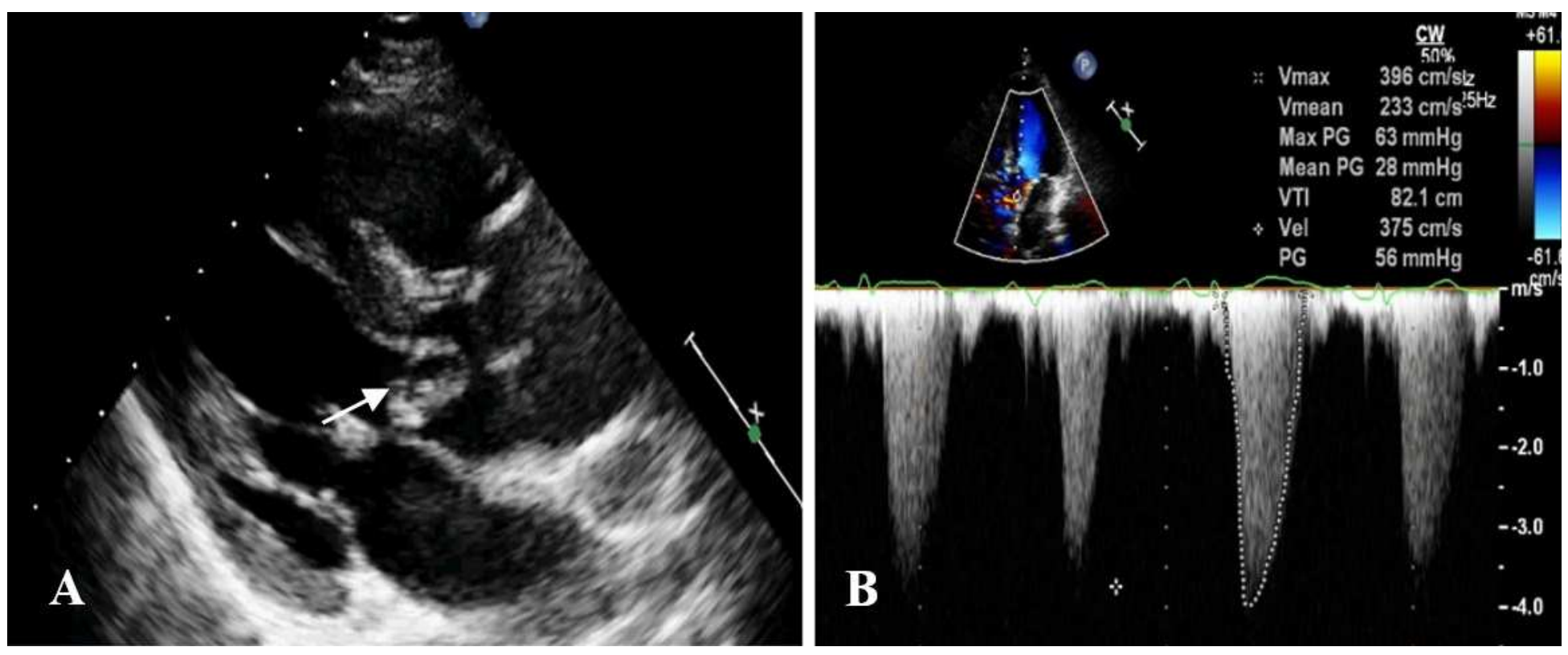

\section{Figure 4}

Case 2. (a)Transthoracic echocardiography in the apical long-axis view showed AMVT (arrow). (b) Continuous Doppler measurement traced the instantaneous gradient of $64 \mathrm{mmHg}$ at the proximal LVOT.

$v_{A}$

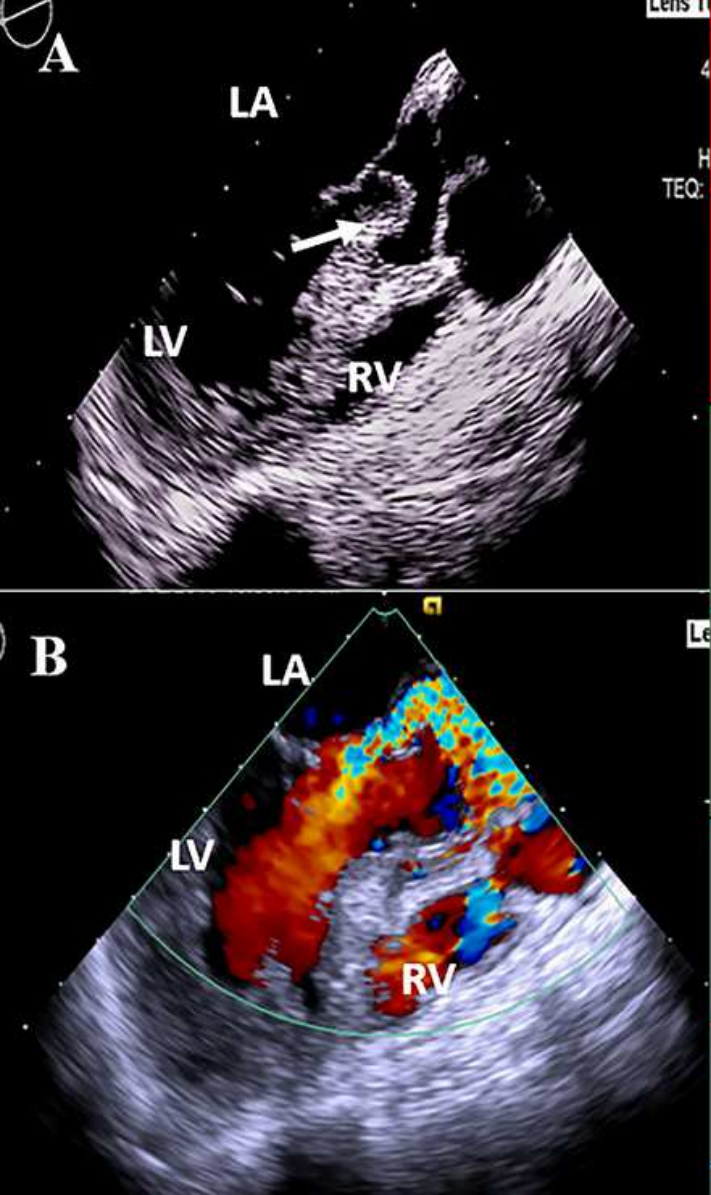

C

Lens Temp: $40.5^{\circ} \mathrm{C}$

$16 \mathrm{vps} / 120 \mathrm{~mm}$

Genera

$--40-$
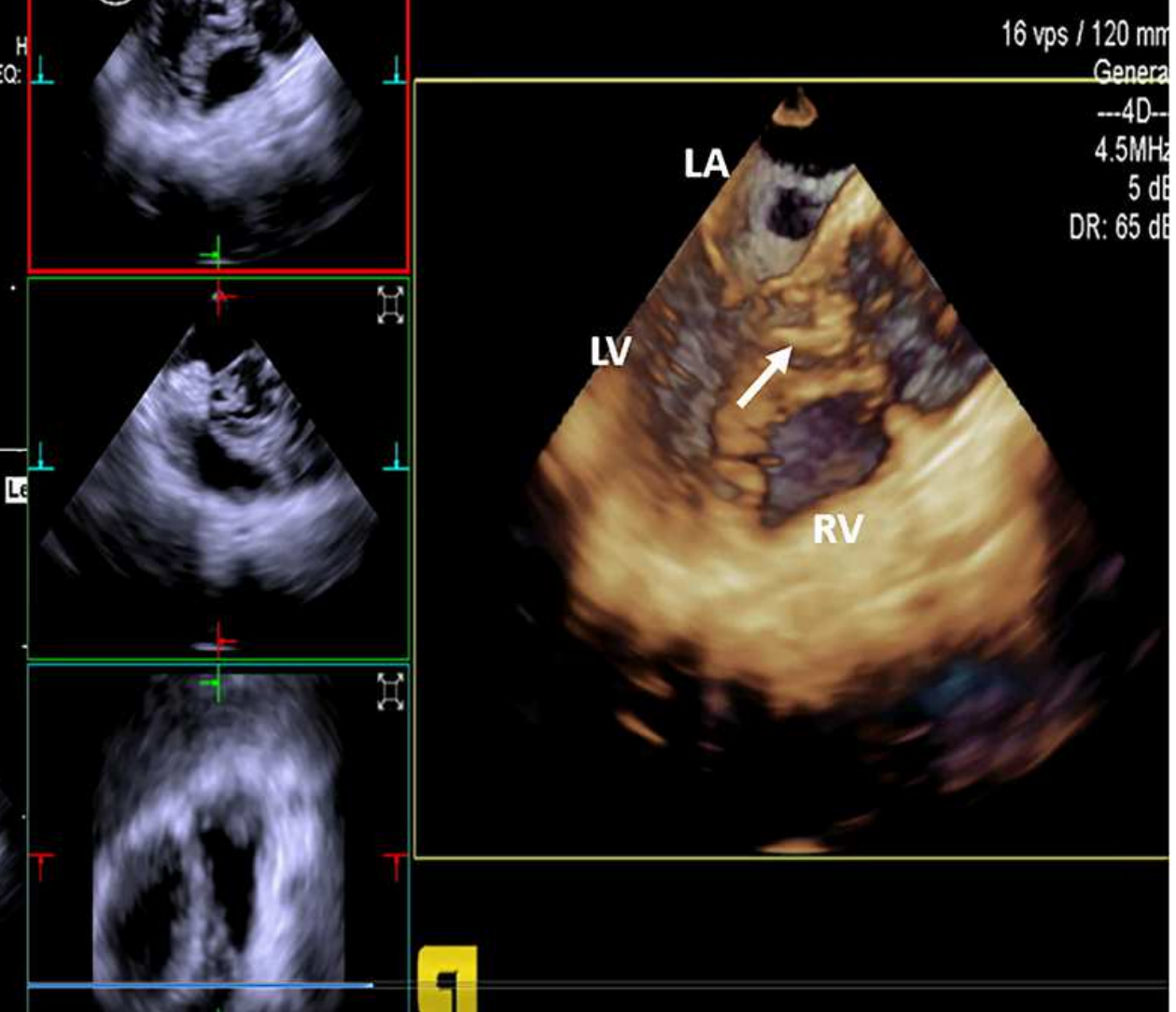

|

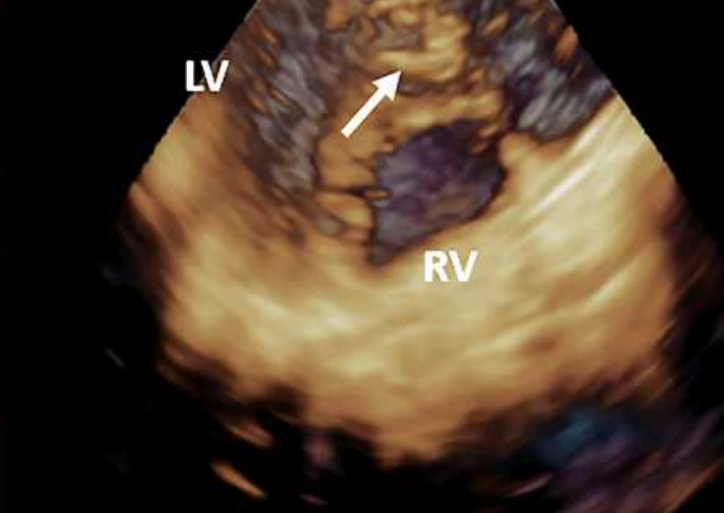

.

Figure 5 
Case 2. (a)TEE,162-degree view, demonstrated the movement of AMVT being folded into LVOT. (b) Aliasing was clearly seen in LVOT with color Doppler flow frame. (c)3D rendering of the AMVT viewed from the bottom of the heart towards the apex in the long-axis view.
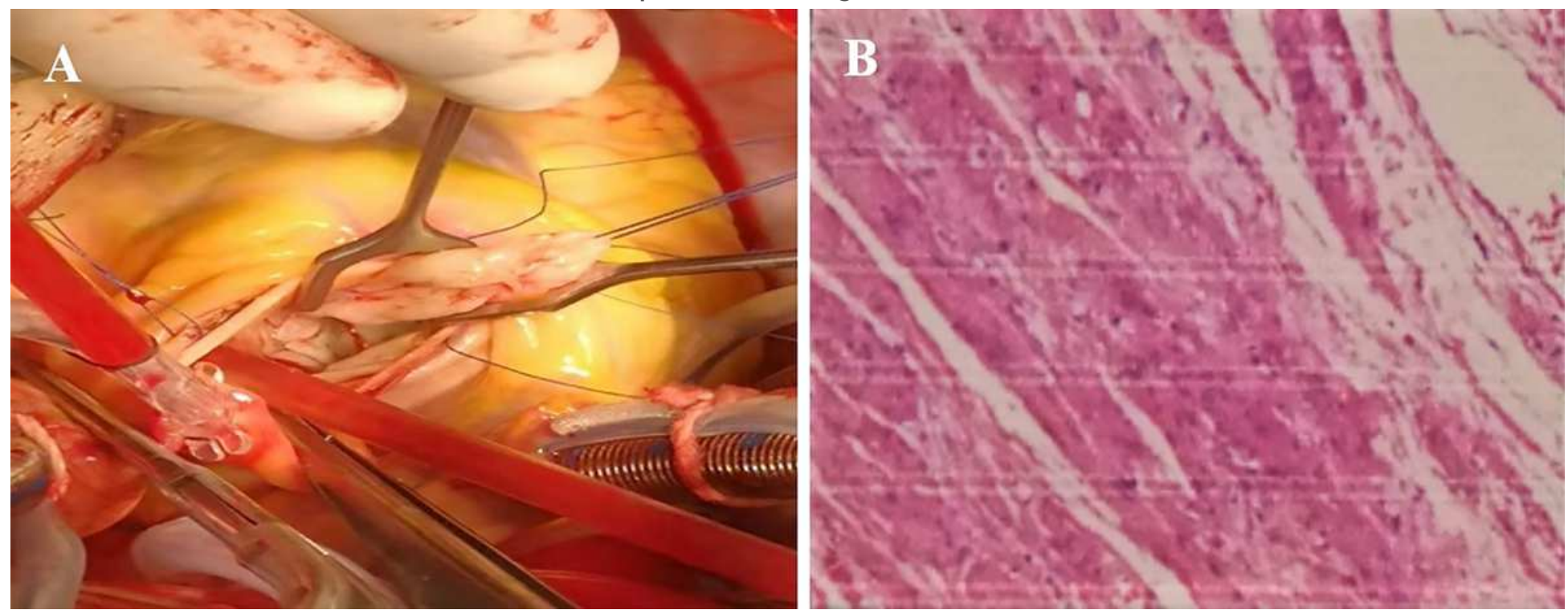

\section{Figure 6}

Case 2. (a)Transaortic excision of a mobile mass resembling a leaflet, attached to the anterior mitral leaflet. (b)Histological examination (Hematoxylin-eosin stain) showed myxomatous degeneration.

\section{Supplementary Files}

This is a list of supplementary files associated with this preprint. Click to download.

- Video1.avi

- Video2.avi

- Video6.avi

- Video7.avi

- Video4.avi

- Video5.avi

- video3.mp4 